\title{
Pediatric Radiology editorial board — acknowledgments and updates
}

\author{
Peter J. Strouse ${ }^{1}$ - Øystein E. Olsen ${ }^{2}$
}

Published online: 26 November 2016

(C) Springer-Verlag Berlin Heidelberg 2016

As editors of Pediatric Radiology we are indebted to the service provided by our Editorial Board members. Individuals are invited to serve on the journal's Editorial Board because of their expertise and experience in the subject matter, their availability and reliability in reviewing manuscripts, and in recognition of other contributions to the journal. We sincerely thank the members of the Editorial Board for their contributions toward the success of our journal.

Editorial Board membership is not honorary. The Editorial Board of Pediatric Radiology is a working editorial board. Editorial Board members do a greater number of reviews and provide reviews on papers that are challenging, controversial or obscure in nature. Editorial Board members also contribute to the journal as subject matter experts. Editorial Board members assist the editors as consultants and by identifying new reviewers to add to our team. Editorial Board members are occasionally asked to contribute commentaries on important and controversial articles and are asked to contribute to the journal in the form of review articles,

Peter J. Strouse

Rad-Ped-Radiol-Journal@med.umich.edu

Øystein E. Olsen

oeolsen.pedrad@me.com

1 Section of Pediatric Radiology, C. S. Mott Children's Hospital, Room 3-231, Department of Radiology,

University of Michigan Health System, 1540 E. Hospital Drive, Ann Arbor, MI 48109-4252, USA

2 Radiology Department,

Great Ormond Street Hospital for Children,

Great Ormond Street, London WC1N 3JH, UK minisymposia or other special projects at least once every 3 5 years. These contributions undergo the standard review process.

We are excited to have several upcoming minisymposia in the journal, each one guest-edited by Editorial Board members. The minisymposia topics will include education, MR techniques, reducing sedation in pediatric MR, quality and practice in pediatric radiology, contrast-enhanced ultrasound, pneumonia, and fetal/neonatal imaging (an update drawn from the upcoming Society for Pediatric Radiology course). We are thankful to the respective Editorial Board members for suggesting and organizing each of these minisymposia and serving as guest editors.

The composition of the Editorial Board of Pediatric Radiology is re-evaluated and updated yearly. The new board takes effect with the January issue of each volume (year). Service is not term-limited.

Success of the journal is dependent on the expertise, guidance and contributions of this community of experts in pediatric imaging and related subjects. We would like to sincerely thank the following outgoing Editorial Board members for their years of excellent service to the journal:

\section{Jacques Schneider (Neuroradiology) \\ Erin Simon-Schwartz (Perinatal)}

We would like to welcome the following incoming Editorial Board members:

Sylviane Hanquinet (Gastrointestinal)

Randall K. Otto (Cardiovascular)

Akshay K. Saxena (Chest)

Keith J. Strauss (Physics and Radiation Dose) 